\title{
Life-cycle Management Research in Power Grid Construction Project
}

\author{
Liu Jinsen ${ }^{1}$, Li Lijuan ${ }^{1}$, Lu Sibin ${ }^{1}$ and Zhang Yan ${ }^{1}$ \\ ${ }^{1}$ Power Grid Planning \& Research Center, Guizhou Power Grid Company \\ Limited, Guizhou Guiyang, 550003, China \\ ${ }^{2}$ Guizhou Power Grid Company Limited, Guizhou Guiyang, 550003, China \\ E-mail:dazhuheshui@163.com
}

\begin{abstract}
The current investment and management mode of power grid construction project is inadequate to the whole optimization, the overall process of the project has obvious time-phased, therefore, the paper strongly advocates to carry out life-cycle management in power grid construction project, and divides the construction project into five stages as preliminary planning, design and planning, construction and operation, scrap and disposal, and evaluate and control the cost of operating stage, investment benefit of decision stage, design stage management and risk of construction stage, and sets up performance evaluation model of power grid project, in order to provide certain practical significance for the establishment of life-cycle management mode of power grid enterprises.
\end{abstract}

Keywords: Life-cycle management; power grid; construction project; evaluation model

\section{Introduction}

The current investment and management mode of power grid construction project emphasizes on the stage division and sequentiality, various stages of planning, procurement, installation, operation and decommissioning disposal of the project are managed and implemented by different departments, there is still insufficient in whole optimization, lack effective coordination on management objective at various stages, the managers of each stage tend to focus on the goal of this stage and problems need to be solved, the consideration of the whole system is not enough, thus often leading to local optimization and stage optimal, but the life-cycle cost optimal of grid construction project is difficult to be achieved [1]. Life-cycle management is a management innovation, which starts from the overall objective in accordance with requirements of the company development strategy and development in different periods, making overall plans and takes all factors into consideration on the relationship among asset security, efficiency, and cycle cost, covering planning, design, procurement, construction, operation and maintenance, financial, performance, and other fields, with the aid of modern information management method, based on the basic theory of system engineering, using multiple designs integration method of modularization, standardization, and streamline, through in-depth study and summarizes the extracted concepts and methods. Therefore, life-cycle management is introduced in power grid construction project, which makes system-wide, overall process and entire-cost management and optimization to stages as preliminary planning, design and planning, equipment procurement, construction and installation, operation and maintenance, recycle, etc. thus has strong theoretical and practical value on the improvement of power grid construction level. 


\section{Life-cycle Theory Basis}

The content of life-cycle management includes the integrated management of assets, time, cost, quality, human resources, communication, risk, and procurement. By organizing and integrating knowledge, and information, to integrate the information of future operation period forward, management cycle turns into life-cycle mode with operation stage as priority from the original project stage, which can more fully consider the opportunities and challenges of project may face to, help to improve the project value. Life-cycle management has two major features of macro prediction and comprehensive control, it considers about the whole life cycle from the planning, design to scrap, thus avoids short-term cost behavior, and ensures the application of LCC method institutionally; the boundary between departments is broken then, gives overall consideration on different stages such as planning, construction, operation, etc., takes enterprise overall benefit as a starting point to seek the optima solution; gives consideration to all the possible costs, and search a balance between appropriate availability and entire cost, so as to find out the LCC minimum solution.

Life-cycle of construction project refers to the whole process from project design to construction project scrap (or the end of construction project). In the life-cycle period, construction project goes through five stages as preliminary planning, design and planning, construction and operation, and scrap disposal, as shown in Figure 1.

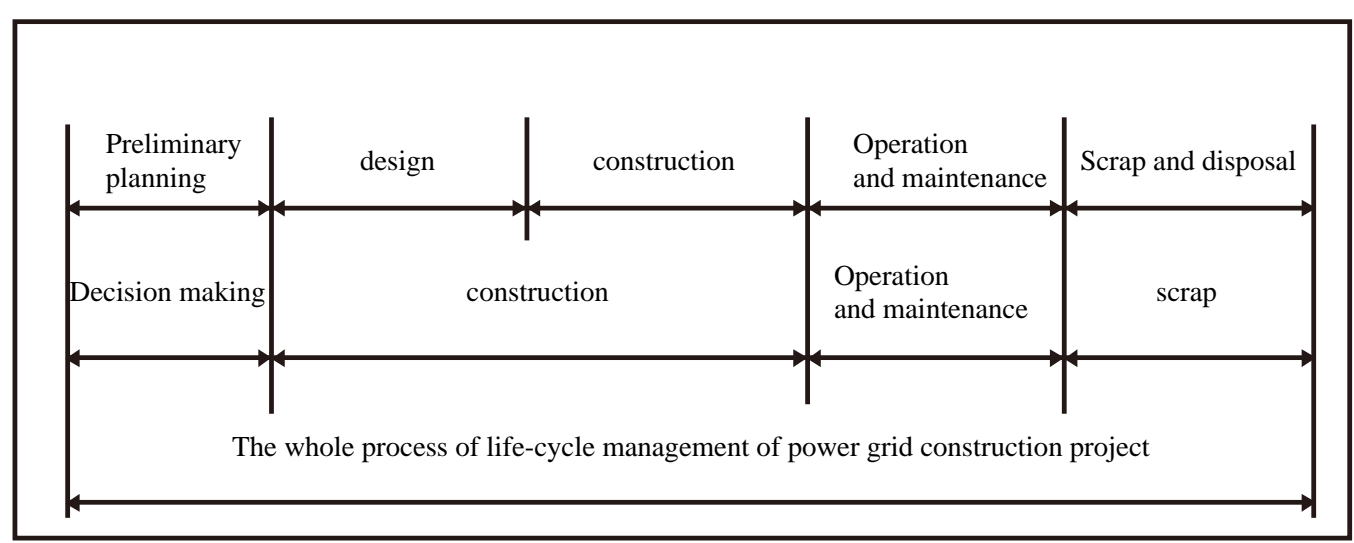

Figure 1. The Whole Process of Life-cycle Management of Power Grid Construction Project

Life-cycle management is a system engineering, which needs systematic and scientific management, to realize the objective of each stage thus ensure the realization of final objective (maximize economic, social and environmental benefits of investment). Life-cycle management throughout the whole process of construction project, and has different characteristics and target in different stages, management of each stage all linked with each other, as shown in Table 1.

Table 1. Life-cycle Management Stage and Objective of Power Grid Construction Project

\begin{tabular}{ccc}
\hline $\begin{array}{c}\text { Stage of life- } \\
\text { cycle } \\
\text { management of } \\
\begin{array}{c}\text { construction } \\
\text { project }\end{array}\end{array}$ & $\begin{array}{c}\text { Operation and } \\
\text { management stage }\end{array}$ & $\begin{array}{c}\text { Maintain the applying function of the } \\
\text { project, control the operating cost of } \\
\text { project }\end{array}$ \\
\cline { 2 - 3 } & $\begin{array}{c}\text { Decision-making } \\
\text { stage }\end{array}$ & $\begin{array}{c}\text { Select suitable construction project, } \\
\text { determine the corresponding investment } \\
\text { objective }\end{array}$ \\
\hline
\end{tabular}




\begin{tabular}{cc} 
Design stage & $\begin{array}{c}\text { To implement investment objective, } \\
\text { prepare reasonable design scheme }\end{array}$ \\
\hline Construction stage & $\begin{array}{c}\text { To realize the security, quality, schedule, } \\
\text { cost objective of the project }\end{array}$ \\
\hline $\begin{array}{c}\text { Scrap recycling } \\
\text { stage }\end{array}$ & $\begin{array}{c}\text { To transform the building waste into } \\
\text { renewable resources and recycled products, } \\
\text { so as to reduce the social and } \\
\text { environmental impact }\end{array}$
\end{tabular}

\section{The Application of Life-cycle Management in Power Grid Construction}

\subsection{Calculation and Control of Operation Cost}

The same amount of money has different values at two different moments of current and future, which is the time value of the cash flow concept. To calculate the time value of cash flow, it usually uses the concept of terminal value and present value of cash flow. To calculate the life-cycle cost of power grid construction project, it shall discount the life-cycle cost to a certain time point for analysis, so the capital time value model is adopted to calculate the net present value ${ }^{\mathrm{C}_{L}}$ of LCC, net annual value ${ }^{\mathrm{C}_{N}}$ of LCC for Life Cycle Cost (Life Cycle Cost, LCC) of power grid construction project.

The calculation of net present value $\mathrm{C}_{L}$ of LCC as shown in formula (1).

$\mathrm{C}_{\mathrm{L}}=\mathrm{C}_{\mathrm{I}}+\mathrm{C}_{\mathrm{O}}+\mathrm{C}_{\mathrm{M}}+\mathrm{C}_{\mathrm{F}}+\mathrm{C}_{\mathrm{D}}=\mathrm{C}_{\mathrm{I}}+\sum_{\mathrm{i}=1}^{\mathrm{n}} \frac{\mathrm{C}_{\mathrm{Oi}}+\mathrm{C}_{\mathrm{Mi}}+\mathrm{C}_{\mathrm{Fi}}}{(1+\alpha)^{\mathrm{i}}}+\frac{\mathrm{C}_{\mathrm{D}}}{(1+\alpha)^{\mathrm{n}}}$

Where, $C_{I}, C_{\mathrm{O}}, C_{M}, C_{F}, C_{D}$ indicates investment cost, operation cost, maintenance cost, failure cost and scrap cost, respectively, $\mathrm{n}$ is calculating design working life, ${ }^{i}$ is annual frequency, $\alpha$ is discount rate.

Table 2. Life-cycle Cost Composition of Power Grid Project

\begin{tabular}{|c|c|c|}
\hline \multirow{16}{*}{$\begin{array}{l}\text { Cost division of life- } \\
\text { cycle of power grid } \\
\text { construction project }\end{array}$} & \multirow{4}{*}{ Investment cost } & Purchase cost \\
\hline & & Install cost \\
\hline & & Construction cost \\
\hline & & Other costs \\
\hline & \multirow{4}{*}{ Operation cost } & Energy consumption cost \\
\hline & & Manpower cost \\
\hline & & Environmental protection cost \\
\hline & & Other costs \\
\hline & \multirow{4}{*}{ Maintenance cost } & monitoring cost \\
\hline & & Repair cost \\
\hline & & Technical modification cost \\
\hline & & Other cost \\
\hline & Failure cost & Power off loss \\
\hline & \multicolumn{2}{|r|}{ Repair cost } \\
\hline & \multicolumn{2}{|r|}{ Other cost } \\
\hline & & crap cost \\
\hline
\end{tabular}


Net annual value is through the cash equivalent conversion, project net present value is shared to equivalent annual value of each year in life-cycle period (from 1 to $n$ ). In order to solve this problem, it adopts the method of net annual value analysis, comparing the equivalent annual value of different schemes LCC sharing in each year, more liable to scheme comparison, the calculation formula as shown in (2).

$\mathrm{C}_{\mathrm{N}}=C_{L} \cdot \frac{\alpha \cdot(1+\alpha)^{n}}{(1+\alpha)^{n}-1}$

In life cycle cost analysis, the LCC calculation results are subjected to the influences of operation term, annual interest rate, the rate of inflation to a certain extent. Therefore, in order to maintain the correctness of the calculation result, it is necessary to modify these economic parameters. First calculate respective life-cycle cost with their operating term of the equipment, then use the following formula to calculate the average annual total life cycle cost $\overline{\mathrm{C}_{L}}$ of $\mathrm{n}$ years, then make correlation analysis and evaluation, the calculation formula as shown in (3).

$\overline{\mathrm{C}_{L}}=\frac{C_{L}}{n}$

The impact of inflation on LCC of power grid construction project is considerable. Especially when the operating life of project is much longer, the influence of inflation shall be considered more. Set the original fund is $C_{A}$, the annual inflation rate in the

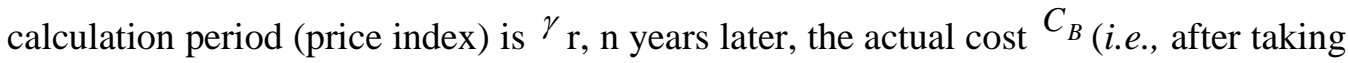
into account the inflation rate) is calculated by formula(4).

$C_{B}=C_{A} \cdot(1+\gamma)^{n}$

It is important to note that the price index varies from year to year in estimation period, and price fluctuation has rises and falls. For computational simplicity, usually it calculates based on the average price index in estimation period, but the calculation results have slightly errors. Therefore, it is better to calculate year by year.

\subsection{The Investment Benefit Calculation of Decision-making Stage}

Net present value index method is put the revenue, expense or net cash flows of each year in life-cycle of project scheme discounting to the algebraic sum of present value according to certain discount rate, and evaluate the index method of the selected project scheme accordingly, its formula as shown in formula (5).

$C_{\mathrm{NPV}}=\sum_{\mathrm{i}=0}^{n}\left[\left(C_{\text {in }}-C_{\text {out }}\right) \cdot(1+i)^{m}\right]$

Where, $C_{\text {in }}, C_{\text {out }}$ represents the cash inflow and cash outflow at $\mathrm{m}$ year, respectively, the difference value of both is net cash flow, set the initial investment of investment project as $C_{\mathrm{L}}$, and the annual net income $P$ of the following years are equal, then formula (5) becomes:

$C_{\mathrm{NPV}}=P \cdot(P \mid i, n)-C_{L}$

When evaluate project scheme with the method of net present value analysis, net present value is positive, which illustrates the scheme can satisfy the requirement of predetermined yield and in addition, the profits. The greater the net present value is, 
the greater the profits are. Net present value is zero, which illustrates it just meets the requirements of the yield, and profit and loss balance; net present value is negative, which indicates that the scheme can not meet the predetermined yield demand, there are losses. Therefore, when $C_{N P V} \geq 0$, the scheme is feasible; while $C_{N P V}<0$, the scheme is infeasible. For multiple repelling schemes, one with maximum NPV should be selected optimally.

The advantage of net present value method is the consideration on time value of capital, at the same time the operation condition of investment project in the whole analysis period. It directly express the yield of return of investment project with amount of money, is more intuitive. But when calculating the net present value, it shall determine a yield of return in advance.

\subsection{Management Evaluation of Design Stage}

With the reform of electric power system, power grid planning in China is basically charged by the power grid company, the objective of power grid planning has been translated from the original total profit maximization of delivery, transportation, distribution into the profit maximization of power grid operation and construction gradually. But the comparative center of current planning and design scheme is still technical comparison, and that is the comparison of the reliability, usually in terms of economical comparison, it still adopts the traditional technical and economic evaluation method, namely the initial investment of the scheme or the annual cost comparison with initial investment as primary, and calculation formula as shown in (7).

$\min C_{A j}=\frac{\alpha(1+\alpha)^{T}}{(1+\alpha)^{T}-1}\left(P_{j}+\sum_{i=1}^{T} \frac{C_{O i}}{(1+\alpha)^{i}}\right)$

Where, ${ }^{P_{j}}$ represents the initial investment of the ith scheme, ${ }^{C_{A j}}$ represents the annual cost of the ith scheme, $\gamma$ is discount rate, $\mathrm{T}$ is the calculation cycle, generally is 10 to 20 years, ${ }^{C_{O i}}$ represents the operation cost of the ith year, through formula (7), to compare the annual cost of various schemes, and select the optimal one.

\subsection{Risk Assessment of Construction Stage}

Construction stage is mainly according to budget control building, installation, equipment, and other practical needs of the construction costs, the bidding by project legal person to select the construction team and equipment materials suppliers, it was decided to construction, installation, equipment, materials, the actual price is the key, is directly related to engineering budget can get control and execution.

The main influencing factors are: (1) social factors, social and economic factors are uncontrollable factors, but it is a direct impact on electric power engineering cost. Social and economic factors are mainly the policy-type charge fee and interest rate changes, land requisition and demolishing cost, etc. The environmental impact assessment consulting fees, policy-type charging rates as survey, design fee, etc. have also increased, which result in an increase in other costs of construction cost directly. And interest rate changes directly affect the interest payment in construction period. (2) Human factors, construction personnel level, management, personnel management level, etc. will have a certain degrees of impact on power grid construction project cost. (3) The natural factors, mainly include force majeure of natural disasters and natural conditions. During the period of power grid construction if there are any force majeure of natural disasters, the time limit for power grid construction project would be influenced, even have a certain destruction to the built power grid, so the impact on the 
cost of power grid is great; also if unfavourable geological condition changes and hydrological condition changes are encountered in power grid construction, which often lead to design changes and increase the difficulty of construction, and the design changes and construction scheme changes will cause the project construction cost increase.

\section{Performance Evaluation of Project Construction}

The power grid enterprises shall reform the existing with three control objectives (investment, construction period, quality) as primary static evaluation model, establish multitasking comprehensive incentive mechanism with the combination of short-term and long-term, static and dynamic, obvious and recessive stimulation, so as to promote the effective implementation of asset life-cycle management in power grid project construction phase.

Considering two categories of objective, denote as $\mathrm{O}_{p}, p=1,2$, where the shortterm objective $O_{1}$ is the control of three objectives in project construction (investment, construction period, quality), long-term objective is the pursuit of future long-term economic operation efficiency and reliability and control of the environmental protection and resource consumption.

Agent's effort behavior corresponding to two categories are ${ }^{a_{1}}$ and ${ }^{a_{2}}$ respectively, which represent the manpower and material resources, financial resources and other resources invested by agent on the two objectives and personnel management ability, the effort behavior of the agent cannot be fully observed by client. Effort output function denotes as $y$, which represents the realization degree of short-term and longterm objective, assuming the output function is linear relation, that is:

$y=f_{1} a_{1}+f_{2} a_{2}+\varepsilon$

Where, $f_{1}$ and $f_{2}$ are the output coefficient of effort behavior, respectively, it can be a positive constant and can also be function of effort behavior ${ }^{a_{1}}$ and ${ }^{a_{2}} ;$ : in order to influence the exogenous random variable of output, and assuming $\varepsilon \in N\left(0, \delta^{2}\right)$.

The effort cost function of the agent is $c$, which represents the negative utility brought to agent from resource investment as manpower, material, financial resources and personnel management ability, so the cost function of effort behavior can be expressed in quadratic function form:

$c=0.5 b_{1} a_{1}^{2}+0.5 b_{2} a_{2}^{2}$

Where, ${ }^{b_{1}}$ and $b_{2}$ is the cost coefficient of effort behavior, respectively, which can be a positive constant and can also be function of effort behavior $a_{1}$ and $a_{2}$.

According to the above assumptions, it can establish principal-agent incentive model between the principal and agent. First considering about the objective function of the principal, that is, to maximize the expected return of the principal: $\max _{t, a_{1}, a_{2}} P=E(y-w)$ Where, $w$ represents the total compensation of client paid for agent. If there is no information asymmetry, the principal can takes compulsory contract directly, and regulates the effort degrees that agent must achieve at. That is to say, the client can maximize formula (10) with $\mathrm{t},{ }^{a_{1}}$ and ${ }^{a_{2}}$ as selecting variables. But, in fact, the principal cannot observe the effort degree of agent directly, so they cannot stipulate the specific effort degree of the agent, while only stimulate the effort behavior of agent according to the observed performance. Considering the constraint of the maximum 
effort degree ${ }^{a_{0}}$ of agent, the short-term and long-term comprehensive stimulation model can be established as follows:

$\max _{t} P=\left(f_{1}-t g_{1}\right) a_{1}+\left(f_{2}-t g_{2}\right) a_{2}-s$

Where, $s$ is fixed remuneration the client paid for the agent, $t$ is the bonus coefficient client paid for the agent (also known as stimulation coefficient).

According to principal-agent theory, the happening order of the above comprehensive simulation model events: (1) the principal and the agent signed in advance compensation stimulation contract $w=t+t p$ based on measurable performance; agent selects effort behavior ${ }^{a_{1}}$ and ${ }^{a_{2}}$, but the principal cannot observe the selection and effort degree of the agent; (3) agent carries on project construction management, the project construction results will be subject to the influences of external random factors $\varepsilon$ and $\xi$ the agent can't control; (4) the effort behavior of the agent and random factors jointly decide the output $y$ and the performance $\mathrm{p}$ observed by principal; (5) the principal and agent perform this stimulation contract, client receives output $\mathrm{y}$ and pay remuneration $\mathrm{w}$ for the agent. In this stimulation model, the client needs to design the optimal stimulation coefficient $t^{*}$, so the agent chooses the optimal effort behavior $a_{1}^{*}$ and $a_{2}^{*}$, thus finally achieve the objective of the client.

In order to test the function of life-cycle management for power grid construction project evaluation, it conducts sensitivity analysis on it, when investment and electricity price changes are $\pm 5 \%$ and $\pm 10 \%$, respectively, it calculates the financial internal rate of return and capital internal rate of return after life-cycle management, and analyzes sensitivity of the two, as shown in Figure 2, Figure 3.

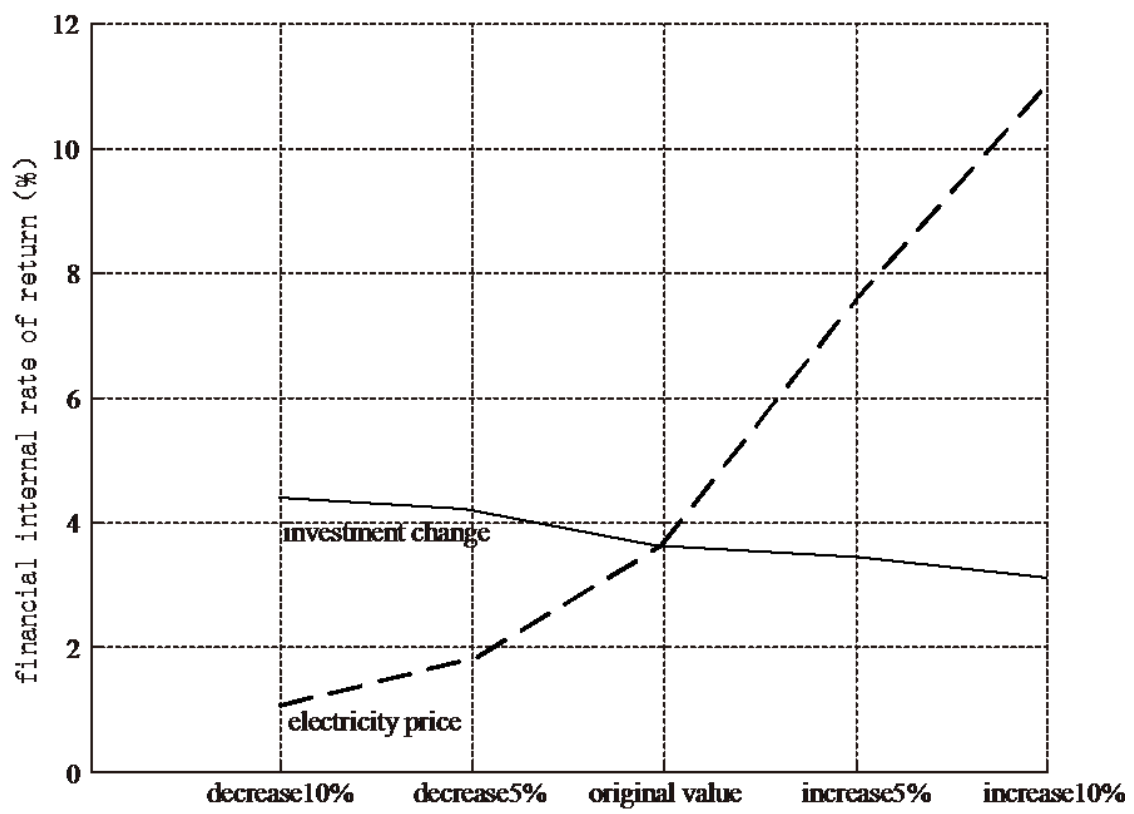

\section{Figure 2. The Financial Internal Rate of Return after Investment and Electricity Price Changes}




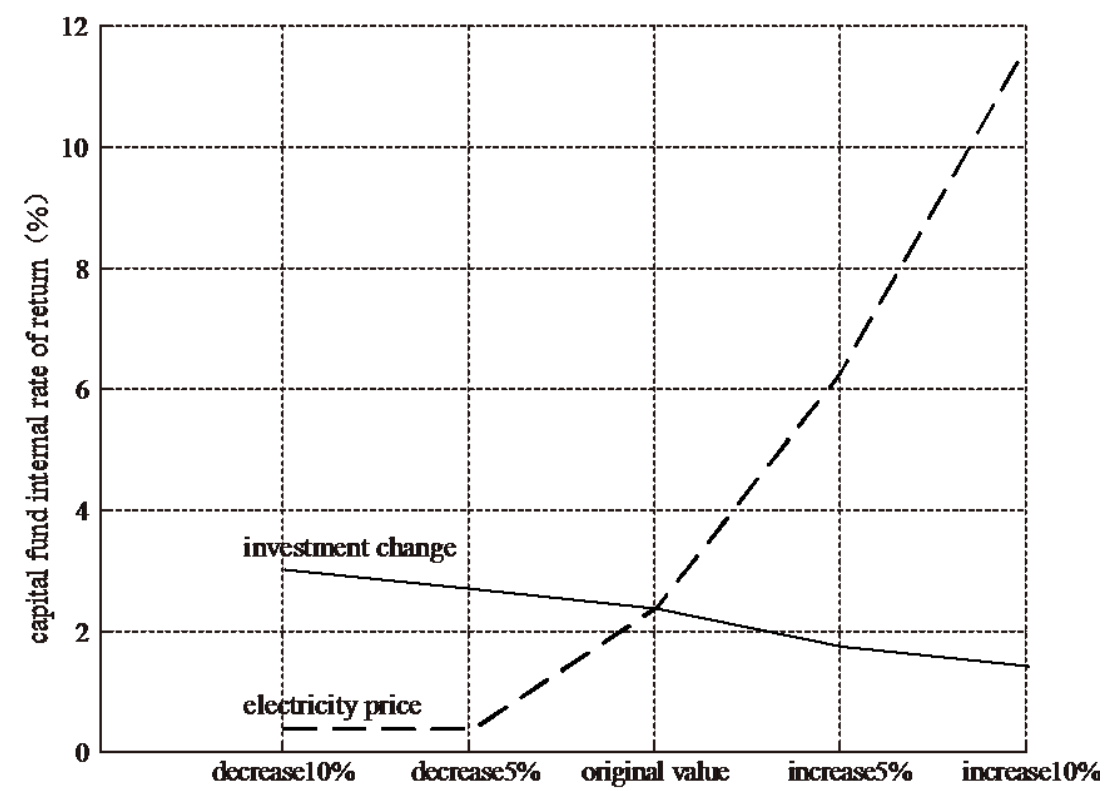

Figure 3. The Capital Fund Internal Rate of Return after Investment and Power Changes

As can be seen from the Figure 2 and Figure 3, electricity sale price changes have great influence on the financial situation in "project", followed by investment. The electricity sale price is increased by $5 \%$, the capital internal rate of return is greater than $10 \%$, which meets the stipulation of "construction project economic evaluation method and parameter (third edition)" on urban network engineering of "financial benchmark yields of project after-tax capital 10\%"; electricity sale price is increase by $10 \%$, and up to 0.406 yuan/(kw.h), financial internal rate of return is up to $10.1 \%$, which is higher than bank long-term loan interest rate of $7.11 \%$, and investment generates profits. Through calculation, electricity sale prices increased by $6.31 \%$, namely increased by $0.023 \mathrm{yuan} /(\mathrm{kw} \cdot \mathrm{h})$, financial internal rate of return is up to $8 \%, 7.11 \%$ more than bank long-term loan interest rate, considering about a certain risk, power grid management enterprises can still get profit; if the electricity sale price increases more than $6.31 \%$, the benefit condition will be improved.

If the power is increased by $5 \%$ and $10 \%$ more based on the predicted growth rate, the financial internal rate of return will increase from $3.45 \%$ to $4.02 \%$ and $4.56 \%$; If the investment reduced by $5 \%$ and $10 \%$, financial internal rate of return will increase from $3.45 \%$ to $3.45 \%$ and $3.56 \%$. it can be know from the sensitivity analysis that, for power grid management enterprises, electricity price is the key factor affecting its financial balance. Because electricity price effects on enterprise income directly, and the electricity sales amount of enterprise is counted as hundred million $\mathrm{kw} \cdot \mathrm{h}$, the slight rise of electricity price, can make it from loss to profit. As shown in calculation example, when the electricity price is $0.023 \mathrm{yuan} /(\mathrm{kw} \cdot \mathrm{h})$, financial internal rate of return is up to $8 \%$, enterprise can profit. Therefore, the use of electricity price is the most direct means to improve the operating conditions of network operation enterprises.

\section{Conclusion}

Life-cycle management of power grid construction project refers to the comprehensive, entire-process management of activities of each stage in life-cycle of power grid engineering project, it through certain forms of organization, and takes the corresponding measures and methods, to plan, coordinate, supervise, control and evaluate all operations of power grid construction project and operational process of 
the system, in order to meet the function and application requirements of construction project, and comply with the purpose of sustainable development, investment benefit improvement. This paper, based on the concept of life-cycle management, makes comprehensive analysis of the important concept of life-cycle management of power grid construction project, and proposes different methods and measures for life-cycle management from the cost analysis and risk management of stages as operation and maintenance, decision-making, design, construction and scrap recycling, etc. in power grid project construction, so as to provide certain practical significances to power grid enterprises to establish the life-cycle management model.

\section{References}

[1] Yishuang Geng, Jin Chen, Ruijun Fu, Guanqun Bao, Kaveh Pahlavan, Enlighten wearable physiological monitoring systems: On-body rf characteristics based human motion classification using a support vector machine, IEEE transactions on mobile computing, 1(1), 1-15, Apr. (2015).

[2] Jie He, Yishuang Geng, Fei Liu, Cheng Xu, CC-KF: Enhanced TOA Performance in Multipath and NLOS Indoor Extreme Environment, IEEE Sensor Journal, 14(11), 3766-3774, Nov. (2014).

[3] Shuang Zhou, Liang Mi, Hao Chen, Yishuang Geng, Building detection in Digital surface model, 2013 IEEE International Conference on Imaging Systems and Techniques (IST), Oct. (2012).

[4] Jie He, Yishuang Geng, Kaveh Pahlavan, Toward Accurate Human Tracking: Modeling Time-ofArrival for Wireless Wearable Sensors in Multipath Environment, IEEE Sensor Journal, 14(11), 3996-4006, Nov. (2014).

[5] $\mathrm{Na} \mathrm{Lu}$, Caiwu Lu, Zhen Yang, Yishuang Geng, Modeling Framework for Mining Lifecycle Management, Journal of Networks, 9(3), 719-725, Jan. (2014).

[6] Yishuang Geng, Kaveh Pahlavan, On the accuracy of rf and image processing based hybrid localization for wireless capsule endoscopy, IEEE Wireless Communications and Networking Conference (WCNC), Mar. (2015).

[7] Guanxiong Liu, Yishuang Geng, Kaveh Pahlavan, Effects of calibration RFID tags on performance of inertial navigation in indoor environment, 2015 International Conference on Computing, Networking and Communications (ICNC), Feb. (2015).

[8] Jie He, Yishuang Geng, Yadong Wan, Shen Li, Kaveh Pahlavan, A cyber physical test-bed for virtualization of RF access environment for body sensor network, IEEE Sensor Journal, 13(10), 3826-3836, Oct. (2013).

[9] Wenhua Huang, Yishuang Geng, Identification Method of Attack Path Based on Immune Intrusion Detection, Journal of Networks, 9(4), 964-971, Jan. (2014).

[10] Guanqun Bao, Liang Mi, Yishuang Geng, Mingda Zhou, Kaveh Pahlavan, A video-based speed estimation technique for localizing the wireless capsule endoscope inside gastrointestinal tract, 2014 36th Annual International Conference of the IEEE Engineering in Medicine and Biology Society (EMBC), Aug. (2014).

[11] Degui Zeng, Yishuang Geng, Content distribution mechanism in mobile P2P network, Journal of Networks, 9(5), 1229-1236, Jan. (2014).

[12] Mingda Zhou, Guanqun Bao, Yishuang Geng, Bader Alkandari, Xiaoxi Li, Polyp detection and radius measurement in small intestine using video capsule endoscopy, 2014 7th International Conference on Biomedical Engineering and Informatics (BMEI), Oct. (2014).

[13] Gan Yan, Yuxiang Lv, Qiyin Wang, Yishuang Geng, Routing algorithm based on delay rate in wireless cognitive radio network, Journal of Networks, 9(4), 948-955, Jan. (2014).

[14] Guanqun Bao, Liang Mi, Yishuang Geng, Kaveh Pahlavan, A computer vision based speed estimation technique for localiz ing the wireless capsule endoscope inside small intestine, 36th Annual International Conference of the IEEE Engineering in Medicine and Biology Society (EMBC), Aug. (2014).

[15] Xinchao Song, Yishuang Geng, Distributed community detection optimization algorithm for complex networks, Journal of Networks, 9(10), 2758-2765, Jan. (2014). 


\section{Authors}

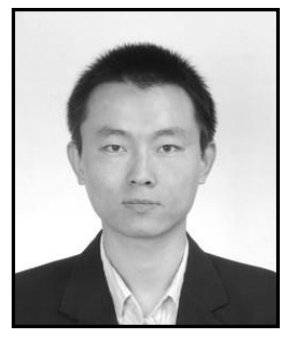

Liu Jinsen, received his M.S. degree in electrical engineering and automation from Guizhou university in Guiyang, China. He is currently a engineer in the Power Grid Planning \& Research Center, Guizhou Power Grid Company Limited. His research interests are mainly concentrated in the area of distribution network planning, security and reliability of power network. He has published several research papers in scholarly journals in the above research areas. 